\title{
The equalization scheme of the residual voluntary health insurance in Slovenia
}

\author{
Boris Zgrablić \\ University of Primorska, Faculty of Mathematics, Natural Sciences and Information \\ Technologies, Glagoljaška ulica 8, SI-6000 Koper, Slovenia \\ TRIGLAV, Health insurance company, Ltd., Pristaniška ulica 10, SI-6000 Koper, Slovenia
}

Received 5 December 2014, accepted 29 December 2014, published online 10 January 2015

\begin{abstract}
Residual voluntary health insurance in Slovenia covers the difference between the (recognised) value of the health service and the part of this value that is payed by the compulsory health insurance. From the inception of compulsory health insurance in 1992, residual voluntary health insurance has open enrolment. From 2006 community rating applied, as well as an equalization scheme with which the differences in health services expenses, arising from the different structures of the insurees of the single insurance undertakings regarding age and gender, shall be equalized. The equalization scheme of the residual voluntary health insurance in Slovenia is presented, along with a detailed explanation of the formulae required for the computation.
\end{abstract}

Keywords: residual voluntary health insurance, equalization scheme, claims equalization, risk equalization.

Math. Subj. Class.: $91 B 30$

\section{Introduction}

In Slovenia, healthcare financing from public sources is organized through compulsory health insurance as a healthcare system of Bismarkian type. The Health Care and Health Insurance Act (HCHIA) [7] regulates both the public compulsory health insurance as well as the private voluntary health insurance.

Although the basket of health benefits for an insuree of the compulsory health insurance is extensive, for a particular health service, the extent of its financing in charge of the compulsory health insurance may, in line with Article 23 of HCHIA, for the majority of

E-mail address: boris.zgrablic@guest.arnes.si (Boris Zgrablić) 
adult insurees vary from $100 \%$ to as low as $10 \%$ of the (recognized) value of the health service; the payment of the difference or the residual amount up to $100 \%$ of the health service value being the obligation of the insuree that received the health service.

Covering the difference or the residual mentioned above is possible through voluntary health insurance of residual type, called residual voluntary health insurance. (The direct translation from Slovenian would be "complementary", but since the term "complementary health insurance" has many different meanings we rather use the word "residual".) Residual health insurance is the most expanded voluntary health insurance in Slovenia, with a dissemination of over $95 \%$ among the insurees of the compulsory health insurance who are liable for residual payments. Nowadays, residual health insurance in Slovenia is offered by three insurance undertakings.

Among all types of voluntary health insurances determined in HCHIA, only the residual health insurance is fully regulated. From its introduction in 1992, open enrollment is its main characteristic. Since 2006, when the reform of residual health insurance applied, community rating is prescribed, with discounts limited to $3 \%$, and late entry loadings of $3 \%$ per year, the total premium rise amounting to at most $80 \%$.

To restrict risk selection in residual insurance, easily achieved through contracting mainly young persons, the legislator decided to introduce the equalization scheme of the residual health insurance, with which the differences in health services expenses, arising from the different structures of the insurees of the single insurance undertakings regarding age and gender, shall be equalized. It is a fact that the purpose of the introduction of the equalization scheme is not given at a legislative level.

The equalization scheme is implemented as a system of transfer of equalization amounts among insurance undertakings. It is calculated ex-post from data included in the reports on the performance of residual insurance for the past equalization period that the insurance undertakings transmit to the ministry, competent for health. Each report contains, for each of the seven age groups (up to 25 years, 25-35, 35-45, 45-55, 55-65, 65-75, above 75 years), for each gender and for each of the three months of the referential equalization period, the number of insurees of the individual insurance undertaking and the health services expenses for the referential period that where accounted up to one month after the referential period, where the health services expenses include the amounts of account claims arising from residual insurance coverage and the amounts accounted as compensations to the health service provider for the transmition of data needed for the functioning of residual health insurance and determined in HCHIA. Also, the report includes, for each age group and for each gender, for each of the three months of each of the three preceding equalization periods, the health services expenses for that preceding equalization period, that where accounted in the three months after the first month of the referential equalization period.

Armstrong, Paolucci and Van de Ven [2] emphasized that a distinction needs to be made between the term "risk equalization" and the term "claims equalization", since besides the ex-ante nature of the first and ex-post of the latter, a major difference is that with the latter insurers have only limited incentives for efficiency as they retain only a limited financial responsibility because both the risk profiles and the claims costs per risk group are equalised, while the former is a mechanism that is used to ensure that risk solidarity 
principles apply, to prevent competition from occurring on the basis of risk selection, and to foster competition based on costs and quality of care. In this sense the equalization scheme of residual voluntary health insurance in Slovenia belongs to the class of claims equalization. A glossary of terms can be found in [1]. The benefits of risk equalization in health insurance markets are discussed in [5, 1]. Stam gives in [4] an insight to testing the effectiveness of risk equalization models in health insurance.

The exact wording of the legislative regulation regarding the equalization scheme of residual voluntary health insurance in Slovenia, that is, a selection of the respective articles of HCHIA, can be found in the Appendix.

The equalizations of differences shall be settled for each equalization period. In Section 2 we give a detailed presentation of all the needed calculations for the ministry, competent for health, to bring a decision about the equalization.

The introduction of an equalization scheme in the specific extremely regulated market of residual voluntary health insurance in Slovenia should be necessarily accompanied by explicit provisions for protection of competition. The lack of such provisions and implications are discussed in [6].

\section{Computation of the equalization amount}

The computation of the equalization amount is described below.

We use the following notation:

$i \quad \ldots \quad$ serial number of the insurance undertaking, included in the equalization in the referential equalization period;

$j \quad \ldots \quad$ serial number of the referential equalization period;

$k \quad \ldots \quad$ relative number of the preceding equalization period with respect to the referential equalization period $(k=0,1,2,3) ; k=0$ stands for the referential period;

$r \quad \ldots \quad$ age group of insurees;

$\mathrm{N}_{r}^{i, j} \quad \ldots \quad$ number of insurees of the insurance undertaking $i$, that in the referential equalization period $j$ belong to the age group $r$; this number is calculated as the average of the numbers of insurees on the first day of every month of the referential equalization period $j$;

$\mathrm{N}_{r}^{i, j, k} \quad \ldots \quad$ number of insurees of the insurance undertaking $i$ that, according to the data on the day of reporting for the referential equalization period $j$, in the preceding equalization period $(j-k)$ belonged to the the age group $r$. The following equalities hold,

$$
\mathrm{N}_{r}^{i, j, k}=\mathrm{N}_{r}^{i, j-k, 0}=\mathrm{N}_{r}^{i, j-k},
$$

since the insurance undertakings ought to have up-to-date data of its insurance contracts.

For further computations the amounts of health service expenses transmitted from insurance undertakings to the ministry, competent for health, in the reports on the performance 
of residual insurance for the past equalization period, are essential. We denote

$\mathrm{AE}_{r}^{i, j, k} \quad \ldots \quad$ amount of health service expenses of the insurance undertaking $i$ within the referential equalization period $j$ relative to the preceding equalization period $(j-k)$ and for the age group $r$. For $k=0$ we denote $\mathrm{AE}_{r}^{i, j, 0}$ as $\mathrm{AE}_{r}^{i, j}$.

The average amount of health service expenses of each insurance undertaking $i$ is calculated for every age group $j$ according to the formula

$$
\overline{\mathrm{AE}}_{r}^{i, j}=\frac{\mathrm{AE}_{r}^{i, j, 0}}{\mathrm{~N}_{r}^{i, j, 0}}=\frac{\mathrm{AE}_{r}^{i, j}}{\mathrm{~N}_{r}^{i, j}}
$$

where

$\overline{\mathrm{AE}}_{r}^{i, j} \quad \ldots \quad$ the average amount of health service expenses of the insurance undertaking $i$ within the referential equalization period $j$ and for the age group $r$.

The average amount of health service expenses of all insurance undertakings, included in the computation, is calculated for each age group according to the formula

$$
\overline{\mathrm{AE}}_{r}^{\bullet, j}=\frac{\sum_{m} \mathrm{AE}_{r}^{m, j}}{\sum_{m} \mathrm{~N}_{r}^{m, j}},
$$

where

$$
\begin{aligned}
\overline{\mathrm{AE}}_{r}^{\bullet, j} \quad \ldots \quad \text { the average amount of health service expenses of all insurance } \\
\text { undertakings included in the computation, within the referential } \\
\text { equalization period } j \text { and for the age group } r .
\end{aligned}
$$

A common rounding policy should be applied.

The standardized number of insurees in an age group of an individual insurance undertaking is calculated for every age group using the formula

$$
\mathrm{SN}_{r}^{i, j}=\sum_{m} \mathrm{~N}_{r}^{m, j} \cdot \frac{\sum_{s} \mathrm{~N}_{s}^{i, j}}{\sum_{m, s} \mathrm{~N}_{s}^{m, j}},
$$

where

$\mathrm{SN}_{r}^{i, j} \quad \ldots \quad$ the standardized number of insurees for the insurance undertaking $i$ within the referential equalization period $j$ and for the age group $r$. 
The standardized amount of health service expenses of an individual insurance undertaking is calculated within an age group $r$ having more than 2000 persons for every equalization period (referential and preceding) according to the formula

$$
\mathrm{SAE}_{r}^{i, j}=\mathrm{SN}_{r}^{i, j} \cdot \overline{\mathrm{AE}}_{r}^{i, j},
$$

where

$\mathrm{SAE}_{r}^{i, j} \quad \ldots \quad$ the standardized amount of health service expenses for the insurance undertaking $i$ within the referential equalization period $j$ and for the age group $r$.

In case the age group $r$ of an individual insurance undertaking contains less than 2000 persons the standardized amount of health service expenses for this age group of this insurance undertaking is given by the formula

$$
\mathrm{SAE}_{r}^{i, j}=\mathrm{SN}_{r}^{i, j} \cdot \overline{\mathrm{AE}}_{r}^{\bullet, j}
$$

The basic equalization amount for the insurance undertaking for the referential equalization period $j$ shall be calculated as the difference between the sum of amounts of expenses for health services in residual insurance of the insurance undertaking in all age groups, and the sum of standardized amounts of expenses for health services in residual insurance of the same insurance undertaking for all age groups. Hence

$$
\mathrm{BEA}^{i, j}=\sum_{r} \mathrm{AE}_{r}^{i, j}-\sum_{r} \mathrm{SAE}_{r}^{i, j},
$$

where

$\mathrm{BEA}^{i, j} \quad \ldots \quad$ the basic equalization amount for the insurance undertaking $i$ for the equalization period $j$.

Let us determine the equalization amount of an insurance undertaking before taking in consideration the (possible) transfered amount (in case in the preceding equalization period the treshold was not attained).

The calculation of the equalization amount of an individual insurance undertaking is based on the comparison of the sum of the positive basic equalization amounts,

$$
\mathrm{BEA}^{\geq, j}=\sum_{\substack{i \\ \mathrm{BEA}^{i, j} \geq 0}} \mathrm{BEA}^{i, j}
$$

where

$\mathrm{BEA}^{\geq, j} \quad \ldots \quad$ the sum of nonnegative basic equalization amounts for the referential equalization period $j$, 
and the sum of negative basic equalization amounts,

$$
\mathrm{BEA}^{<, j}=\sum_{\substack{i \\ \mathrm{BEA}^{i, j}<0}} \mathrm{BEA}^{i, j}
$$

where

$$
\begin{array}{ll}
\mathrm{BEA}^{<, j} \quad \ldots \quad \begin{array}{l}
\text { the sum of negative basic equalization amounts for the referential } \\
\text { equalization period } j .
\end{array}
\end{array}
$$

If the conditions of Article 62.h of HCHIA are met, that is, if the equalization treshold is not attained, a transfer of equalization amounts in the subsequent equalization periods is carried. So for the insurance undertaking $i$ and the equalization period $j$, the computing procedure determines first the equalization amount before taking into consideration the transfer , denoted $\mathrm{EAB}^{i, j}$, where

$$
\mathrm{EAB}^{i, j}= \begin{cases}\mathrm{BEA}^{i, j}, & \text { if }\left(\mathrm{BEA}^{i, j} \geq 0\right) \text { and }\left(\mathrm{BEA}^{\geq, j} \leq-\mathrm{BEA}^{<, j}\right) ; \\ \mathrm{BEA}^{i, j}, & \text { if }\left(\mathrm{BEA}^{i, j}<0\right) \text { and }\left(\mathrm{BEA}^{\geq, j}>-\mathrm{BEA}^{<, j}\right) ; \\ \mathrm{BEA}^{i, j} \cdot \frac{\left(-\mathrm{BEA}^{<, j}\right)}{\mathrm{BEA}^{\geq, j}}, & \text { if }\left(\mathrm{BEA}^{i, j} \geq 0\right) \text { and }\left(\mathrm{BEA}^{\geq, j}>-\mathrm{BEA}^{<, j}\right) ; \\ \mathrm{BEA}^{i, j} \cdot \frac{\mathrm{BEA}^{\geq, j}}{\left(-\mathrm{BEA}^{<, j}\right)}, & \text { if }\left(\mathrm{BEA}^{i, j}<0\right) \text { and }\left(\mathrm{BEA}^{\geq, j} \leq-\mathrm{BEA}^{<, j}\right)\end{cases}
$$

We remark that for the $k$-th preceding equalization periods, $k=1,2,3$, the ministry, competent for health - taking into account the data from the reports on the performance of residual insurance for the referential equalization period about the health services expenses for the $k$-th preceding equalization period, that were accounted in the period of three months after the first month of the referential equalization period - once again executes the computation of the equalization amount before taking into consideration the transfer, that is, the updated $\mathrm{EAB}^{i, j-k}$, and adds up to $\mathrm{EAB}^{i, j}$ (the equalization amount before taking into account the transfer, obtained by taking into consideration only the referential equalization period) the difference between the updated $\mathrm{EAB}^{i, j-k}$ and the previously computed $\mathrm{EAB}^{i, j-k}$ in the then-referential equalization period $(j-k)$.

The equalization amount of the insurance undertaking is equal to the sum of the equalization amount of this insurance undertaking before the transfer (for the referential equalization period) and the transfered equalization amount (from the preceding equalization period), that is,

$$
\mathrm{EA}^{i, j}=\mathrm{EAB}^{i, j}+\mathrm{TEA}^{i, j-1}
$$

where

$\mathrm{EA}^{i, j} \quad \ldots \quad$ the equalization amount of the insurance undertaking $i$ for the equalization period $j$;

$\mathrm{TEA}^{i, j-1} \quad \ldots \quad$ the transfered equalization amount of the insurance undertaking $i$ from the equalization period $(j-1)$ to the equalization period $j$, calculated as described below. 
We first consider the threshold attainment testing.

In case the sum of all positive equalization amounts for the referential equalization period does not attain the equalization threshold for the referential equalization period, being equal to one and a half percent of the health services expenses, the equalization for the referential equalization period is not performed, and the equalization amounts are transfered to the subsequent referential equalization period.

The equalization threshold for the referential equalization period $j$ is calculated as follows:

$$
\operatorname{THR}^{\bullet, j}=1,5 \cdot \sum_{\substack{i, r \\ k=0,1,2,3}} \mathrm{AE}_{r}^{i, j, k} .
$$

The equalization in the referential equalization period is performed if the following condition is met:

$$
\sum_{\substack{i \\ \mathrm{EA}^{i, j} \geq 0}} \mathrm{EA}^{i, j} \geq \mathrm{THR}^{\bullet, j} .
$$

In the referential equalization period the insurance undertaking is a payer in the equalization if its equalization amount for this equalization period is negative, otherwise the insurance undertaking is a receiver in the equalization. In this case the transfered equalization amount of the insurance undertaking $i$ from the referential equalization period $j$ to the subsequent referential equalization period $(j+1)$ equals zero, that is, $\mathrm{TEA}^{i, j-1}=0$.

If the condition for performing equalization from the preceding paragraph is not met, then the equalization is not performed, the transfered equalization amount of the insurance undertaking $i$ from the referential equalization period $j$ to the subsequent referential equalization period $(\mathrm{j}+1)$ is equal to the equalization amount of the insurance undertaking $i$ for the referential equalization period $j$, that is, $\mathrm{TEA}^{i, j}=\mathrm{EA}^{i, j}$.

\section{Appendix - The legislative wording}

The equalization scheme of the residual voluntary health insurance as a method of risk equalization is regulated within the Health Care and Health Insurance Act (HCHIA) [7]. A selected list of provisions follows (translation from Slovenian by Liliane Strmčnik).

\section{Article 62.d}

The insurance undertakings providing residual insurance shall be included in the equalization scheme of residual insurance, with which the differences in health services expenses, arising from the different structures of the insurees of the single insurance undertakings regarding age and gender, shall be equalized. Health services expenses shall include the amounts of account claims arising from residual insurance coverage and the amounts accounted as compensations for the ensured data from point 7 of the second paragraph of Article 62 of this Act. The amount of these compensations shall be agreed between the insurance undertakings and the providers of health services as a percentage of the amounts of the gross account of claims, at the most up to 0,75 percent.

The insurance undertakings providing residual insurance shall keep account records on 
the health services expenses for each insuree. Health services providers shall be bound to transmit the insurance undertakings all the necessary data.

The insurance undertakings providing residual insurance shall participate in the calculation of equalization amounts and in the equalization of differences. The insurance undertakings starting to perform residual insurance shall be exempted from participating in the calculation of equalization amounts and in the equalization of differences for the period of the first twelve months of operation in the field of residual insurances.

\section{Article 62.e}

The basic equalization amount for the insurance undertaking shall be calculated as the difference between the amount of expenses for health services in residual insurance of the insurance undertaking and the standard amount of expenses for health services in residual insurance of the same insurance undertaking. Should the first amount of expenses be lower than the second, the insurance undertaking shall be payer in the equalization otherwise it shall be receiver in the equalization.

The equalization amount shall be calculated for the insurance undertaking by preserving its basic equalization amount or proportionally reducing it in such a way that the sum of the equalization amounts of the payers as well as the sum of the equalization amounts of the receivers shall be equal to the lower of the sum of the basic equalization amounts of the receivers and the sum of the basic equalization amounts of the payers.

The amount of health services expenses in residual insurance of the insurance undertaking shall be the sum of health services expenses arising from the coverage of residual insurance, increased for the amount of compensations for the ensured data from the preceding article. Into account shall be taken the health services expenses that shall have been accounted up to the last day inclusive of the month after the close of the equalization period.

The standardized amount of health services expenses in residual insurance shall be the sum of standardized amounts of expenses according to age groups in the insurance undertaking. The standardized amount of health services expenses in residual insurance for an age class in the insurance undertaking equals the product of:

1. the average amount of health services expenses for an insuree in the insurance undertaking within this age class or, if the age class in the insurance undertaking comprehends less than 2.000 persons, the average amount of health services expenses for an insuree in all insurance undertakings within this age class;

2. the number of insurees in residual insurance within this age class in all insurance undertakings providing residual insurance and participating in the calculation of equalization amounts, and

3. the quotient of the number of insurees in residual insurance in the insurance undertaking and the number of all insurees in residual insurance in all insurance undertakings providing residual insurance and participating in the calculation of the equalization amounts.

The average amount of health services expenses for an insuree in an insurance undertaking within an age class from point 1 of the preceding paragraph shall be determined so that the sum of all health services expenses of the insurance undertaking within the age class is divided by the number of insurees in the insurance undertaking within the same age class.

The number of insurees in residual insurance in the insurance undertaking shall be the average number of insurees on the first day of each month within the equalization period, for which on that same day the insurance undertaking shall bear the responsibility of payment for the health services expenses from residual insurance.

Age groups by gender and age shall start, separately for men and women, at the age of 15 and follow one another within the span of ten years up to the age of 75 . The last 
age groups, separated by gender and age, shall be represented by the insurees aged 75 and more. The insurees who have not yet attained the age of 15 belong to the first two groups.

The age of the insuree in residual insurance shall be reckoned as the age attained within the calendar year. The equalization period shall be a period of three successive calendar months. The first equalization period within a calendar year shall start with the first day of the calendar year.

\section{Article 62.f}

The payer insurance undertaking shall be obliged to pay the equalization amount to the receiver insurance undertakings.

The ministry competent for health shall bring a decision about the equalization. Unless otherwise stipulated by this Act, for the decision procedure of the ministry, competent for health, the provisions of the Act regulating the general administrative procedure shall be applied.

The equalizations of differences shall be settled for each equalization period. For the calculation of the equalization of differences in health services expenses between insurance undertakings, the latter shall be bound to transmit to the ministry, competent for health, the reports on the performance of residual insurance for the past equalization period within 20 days after the end of the month following an individual equalization period.

Upon receipt of the reports from the preceding paragraph, the ministry, competent for health, shall hand over these reports to each of the insurance undertakings within 8 days. The insurance undertaking may give a statement on these reports within 8 days upon receipt of the reports. Should the insurance undertaking refer to documentary evidence in its statement, it should enclose these documents to the statement. Should the insurance undertaking not enclose the documentary evidence to its statement, the ministry competent for health shall take into account only the evidence enclosed to the statement for making its decision.

The ministry competent for health shall decide about the equalization in a written order on equalization without an appointed day within at most 15 days upon expiry of the terms from the preceding paragraph. In its written order the Ministry, competent for health, shall state which insurance undertakings are the payers and which are the receivers in the equalization scheme and the amounts that the payer insurance undertakings shall pay on the accounts of the receiver insurance undertakings. The accounts of the insurance undertakings shall be stated in the written order.

The payer insurance undertaking shall pay the equalization amount within 8 days upon receipt of the written order on equalization. In case of delay in payment, the insurance undertaking shall be obliged to pay legal interests on arrears according to the Legal Penalty Rate Act (Official Gazette RS, no. 56/03).

For the time from the expiry of the equalization period until the issue of the written order on equalization, interest shall accrue in the amount of average pondered interest rate on the inter-bank money market. The ministry competent for health shall decide about the obligation of interest payment in the written order on equalization.

The ministry, competent for health, may call for a debate if it estimate it necessary for the clarification or for the ascertainment of the decisive facts. In this case the insurance undertakings may give their statements in oral form as well, at the debate.

The insurance undertaking in a state member of the European Union, acting within the frame of the European Union and being authorized, in accordance with the Insurance Act, to perform insurance business on the territory of the Republic of Slovenia either through a branch office or directly, shall appoint, for the duration of providing residual insurance business, a mandatory for the delivery of the written orders of the ministry 
competent for health. The insurance undertaking shall notify the ministry, competent for health, on the data about its authorized mandatory for delivery. For the time during which the insurance undertaking has no authorized mandatory for delivery or before notification of his data to the ministry competent for health, the written orders shall be delivered by publication on the notice board of the ministry, competent for health.

The detailed instructions on the contents of the report shall be stipulated by the minister, competent for health.

The detailed instructions for accounting monitoring and statement of business events regarding the performance of equalization shall be stipulated by the Insurance Supervision Agency.

$\ldots$

\section{Article 62.h}

Equalization of differences in expenses for health services shall not be performed for the equalization periods in which the sum of the amounts for equalization that the payer insurance undertakings are obliged to pay is lower than one and a half percent of the amounts of gross calculated claims, increased for the amount of compensation for ensuring the data from point 7 of the second paragraph of Article 62 of this Act. The ministry, competent for health shall state, in a written order, that equalization shall not be performed. Should equalization not be performed in a particular accounting period, the equalization amount shall be transferred to the next accounting period, added to the sum from the prepreceding sentence and taken into account for equalization.

Ackowledgement. The author is grateful to Ivan Gracar for all the fruitful conversations [3] and common work that supported this paper, in the year 2005 and on.

\section{References}

[1] J. Armstrong, F. Paolucci, H. McLeod, W.P.M.M van de Ven, Risk equalization in voluntary health insurance markets: A three country comparison, Health Policy 98 (2010), 39-49.

[2] J. Armstrong, F. Paolucci, W.P.M.M van de Ven, Editorial: Risk equalization in voluntary health insurance markets, Health Policy 98 (2010), 1-2.

[3] Ivan Gracar, personal communication from 2005 on.

[4] P. J. A. Stam, Testing the effectiveness of risk equalization models in health insurance - A new method and its application, PhD Thesis, Erasmus University, Rotterdam, 2007.

[5] W. P. M. M Van de Ven, R.P. Ellis, Risk adjustment in competitive health plan markets, in: Handbook of health economics, vol. 1, ed. A.J. Culyer and J.P. Newhouse, Elsevier Science BV, Amsterdam, 2000, 755-845.

[6] B. Zgrablić, The equalization scheme of residual voluntary health insurance in Slovenia and protection of competition, in preparation.

[7] Health Care and Health Insurance Act, Official Gazette of the Republic of Slovenia no. 9/1992 and further (in Slovenian). 